\title{
Geologia
}

\section{Síntese Geológica e Geocronológica do Cráton São Luís e do Cinturão Gurupi na Região do Rio Gurupi (NE-Pará / NW-Maranhão)}

\author{
Evandro Luiz Klein ${ }^{1}$ (eklein@amazon.com.br) \& Candido Augusto Veloso Moura ${ }^{2}$ \\ ${ }^{1}$ Serviço G eológico do Brasil - CPRM \\ Av. Dr. Freitas 3645, CEP 66095-110, Belém, PA, BRA \\ ${ }^{2}$ Centro de G eociências - Laboratório de Geologia Isotópica - UFPA, Belém, PA, BRA
}

Palavras-chave: geocronologia, litoestratigrafia, Paleoproterozóico, Gurupi, Cráton São Luís.

RESUMO

A região do Gurupi, na fronteira norte dos estados do Pará e Maranhão, é historicamente dividida em dois domínios geocronológicos (Rb-Sr, K-Ar): um paleoproterozóico (Cráton São Luís), outro neoproterozóico (Cinturão Gurupi). Dados geocronológicos em zircão (evaporação de $\mathrm{Pb}$ ), recentemente disponibilizados, além de dados inéditos aqui apresentados, contemplam a maioria das unidades litoestratigráficas e litodêmicas regionais e, juntamente com poucos dados de Sm-Nd em rocha total, mostram ser o período entre 2,0 e 2,2 Ga a época de formação da quase totalidade das unidades rochosas (juvenis ou não). Apenas um granitóide possui idade de cristalização neoproterozóica ( $0,55 \mathrm{Ga})$ e o Arqueano apresenta-se somente como vestígio em cristais herdados de zircão e em idades modelo $\mathrm{Sm}-\mathrm{Nd}\left(\mathrm{T}_{\mathrm{DM}}\right)$ de protólitos de algumas unidades. A avaliação das características composicionais, metamórficas, estruturais, geofísicas e geocronológicas das diversas unidades sustenta a divisão prévia em dois domínios, mas mostra que o domínio (cinturão) Gurupi possui história orogênica paleoproterozóica comum ao domínio (cráton) São Luís. O domínio Gurupi possui características de orógeno colisional, enquanto que o domínio São Luís possui características acrescionárias e ambos participaram da colagem orogênica Paleoproterozóica (2,2 - 2,0 Ga), muito importante em escala global. No Neoproterozóico, a borda sul desse conjunto foi afetada por forte atividade tectônica direcional e litogênese muito limitada, como reflexo da colagem orogênica Brasiliana, definindo a configuração atual do Cinturão Gurupi e da borda sul do Cráton São Luís.

Keywords: geochronology, lithostratigraphy, Paleoproterozoic, Gurupi Belt, São Luís Craton.

\begin{abstract}
The Gurupi region in northern Brazil has been divided into Paleoproterozoic (São Luís Craton) and Neoproterozoic (Gurupi Belt) geochronological domains based on $\mathrm{Rb}-\mathrm{Sr}$ and $\mathrm{K}$-Ar. Recent zircon ( $\mathrm{Pb}$ evaporation) dating of most of the lithostratigraphic and lithodemic units, in addition to limited whole-rock Sm-Nd determinations, shows virtually all rock units (juvenile or reworked) formed between $\sim 2.0 \mathrm{Ga}$ and $2.2 \mathrm{Ga}$. A single granitoid shows a Neoproterozoic crystallization age $(\sim 0,55 \mathrm{Ga})$, and the Archean has been recorded only in inherited zircons and in protolith Sm-Nd model ages. The compositional, metamorphic, structural, geophysical and geochronological characteristics of the geological units supports the previous subdivision into two domains. However, they also reveal a common Paleoproterozoic evolution of both the Gurupi and São Luís domains. The Gurupi domain is characterized as a collisional orogen, whereas the São Luís domain shows accretionary characteristics, with both participating in the widespread Paleoproterozoic collage at 2.2 - 2.0 Ga. During the Neoproterozoic, the southern border of this region was affected by strong strike-slip shearing and very limited lithogenesis, reflecting the Brasiliano orogenic collage elsewhere and defining the presently observed relationship between the São Luís Craton and the Gurupi Belt.
\end{abstract}




\section{INTRO DUÇÃO}

Na região limítrofe entre os estados do Pará e Maranhão (região do Gurupi) afloram rochas ígneas e metamórficas recobertas por sedimentação fanerozóica, ocupando parte da Província Estrutural Parnaíba (Hasui et al., 1984) que integra a atual Plataforma sul-americana (Almeida et al., 2000). Essa cobertura sedimentar extensa e, principalmente, as peculiaridades geomorfológicas da região (muito plana, intenso intemperismo), dificultam sobremaneira o estabelecimento das relações de contato entre as diferentes unidades geológicas. A geocronologia possui papel fundamental em tais situações.

Estudos geocronológicos pioneiros (Hurley et al., 1967; Almeida et al., 1968; Cordani et al., 1968; Almaraz \& Cordani, 1969) permitiram a delimitação de dois domínios distintos nessa região, com base nos métodos Rb-Sr e K-Ar. A nortenordeste, foi distinguido um domínio paleoproterozóico, com rochas apresentando idades em torno de 2,0 Ga; a sulsudoeste, um domínio neoproterozóico, com rochas de idades variadas, principalmente entre 1,0 e 0,5 Ga. Esses domínios passaram a ser denominados, respectivamente, Cráton São Luís e Cinturão Gurupi (Almeida et al., 1976), e serão tratados aqui, genericamente, como domínios São Luís e Gurupi (Figura 1). Fragmentos menores relacionados ao domínio São Luís afloram mais a leste, próximo à cidade de São Luís (Suíte Rosário, Gorayeb et al., 1999) e possivelmente no limite noroeste da Província Borborema (Médio Coreaú - Brito Neves et al., 2000).

Costa et al. (1977), Abreu et al. (1980) e Hasui et al. (1984), principalmente, estabeleceram as primeiras grandes subdivisões litoestratigráficas para a região. Posteriormente, o mapeamento geológico em escala regional executado pela CPRM (Pastana, 1995; Almeida, 2000; Costa, 2000) permitiu a reestruturação da litoestratigrafia previamente estabelecida. Se, por um lado, a cartografia regional apresentou bom avanço, na escala de trabalho, o empilhamento estratigráfico e a precisão cronológica do posicionamento da maioria das unidades litoestratigráficas e litodêmicas permaneceram discutíveis, uma vez que muitas das relações de contato não puderam ser estabelecidas, e visto que o empilhamento baseou-se no acervo de dados $\mathrm{Rb}-\mathrm{Sr}$ e K-Ar (há unidades posicionadas no intervalo Arqueano/Paleoproterozóico), na correlação com outras áreas (p. ex. Cráton Amazônico) e em modelos evolutivos.

Evolução e significado geotectônico de diversas unidades são também objeto de debate. Seqüências metavulcanosedimentares aflorantes nos domínios Paleoproterozóico e Neoproterozóico têm sido consideradas como uma mesma seqüência, diferindo na extensão do retrabalhamento tectônico a que foram submetidas nos diferentes domínios; ou sequiências distintas, formadas em bacias e épocas diferentes (Pastana, 1995; Gorayeb et al., 1999). Diversos corpos de granitóides apresentam diferenças composicionais, petrográficas, estruturais, metamórficas e na associação de campo, o que pode estar refletindo diferentes gerações e/ ou evolução. A evolução do domínio Gurupi tem sido discutida em termos de monocíclica (Costa \& Ricci, 1995) ou policíclica (Pastana, 1995) e o seu significado geotectônico é também controverso, sendo considerado faixa móvel neoproterozóica (Brito Neves \& Cordani, 1991; Costa \& Ricci, 1995) ou cinturão de cisalhamento colisional (Costa \& Hasui, 1997).

A partir da utilização do método de evaporação de $\mathrm{Pb}$ em monocristais de zircão pelo Laboratório de Geologia Isotópica (PARÁ-ISO) da Universidade Federal do Pará, a maioria das unidades regionais passou a contar com dados geocronológicos mais precisos (Klein \& Moura, 2001a, b; Palheta, 2001; Klein et al., 2002). A síntese desses dados será apresentada neste trabalho, além de dados inéditos para o Complexo Maracaçumé, Granito Areal ( $\mathrm{Pb}-\mathrm{Pb}$ em zircão) e Granito Jonasa (Rb-Sr). Um sumário das principais características das unidades litoestratigráficas e litodêmicas será também apresentado. A integração dessas informações propiciou o reordenamento litoestratigráfico, embora ainda parcial, e permite novos avanços no entendimento da evolução geológica regional e uma reavaliação preliminar do significado geotectônico do domínio Gurupi.

Os procedimentos de separação mineral, análise e interpretação das idades aqui utilizadas, bem como uma avaliação sobre a potencialidade e problemas do método de datação de monocristais de zircão por evaporação de $\mathrm{Pb}$ (Pb-Pb em zircão) encontram-se em Klein \& Moura (2001a e suas referências). Análises $\mathrm{Rb}-\mathrm{Sr}$ em rocha total e em minerais foram feitas no PARÁ-ISO, segundo procedimentos descritos por Barbosa \& Lafon (1996).

\section{SÍNTESE LITOESTRATIGRÁFICA E GEOCRONOLÓGICA}

Neste item serão sintetizadas as principais características das unidades litoestratigráficas e litodêmicas. Não serão discutidas todas as redefinições pelas quais passaram algumas unidades. Serão utilizadas, em geral, as denominações originais e as mais recentes, baseadas na concepção vigente a partir de Pastana (1995), Almeida (2000) e Costa (2000). Também serão sumariados os dados geocronológicos históricos dos métodos Rb-Sr (Tabela 1) e K-Ar (Tabela 2), além dos dados mais recentes, obtidos pelo método de evaporação de $\mathrm{Pb}$ em monocristais de zircão e $\mathrm{Sm}-\mathrm{Nd}$ em rocha total (Tabela 3). 


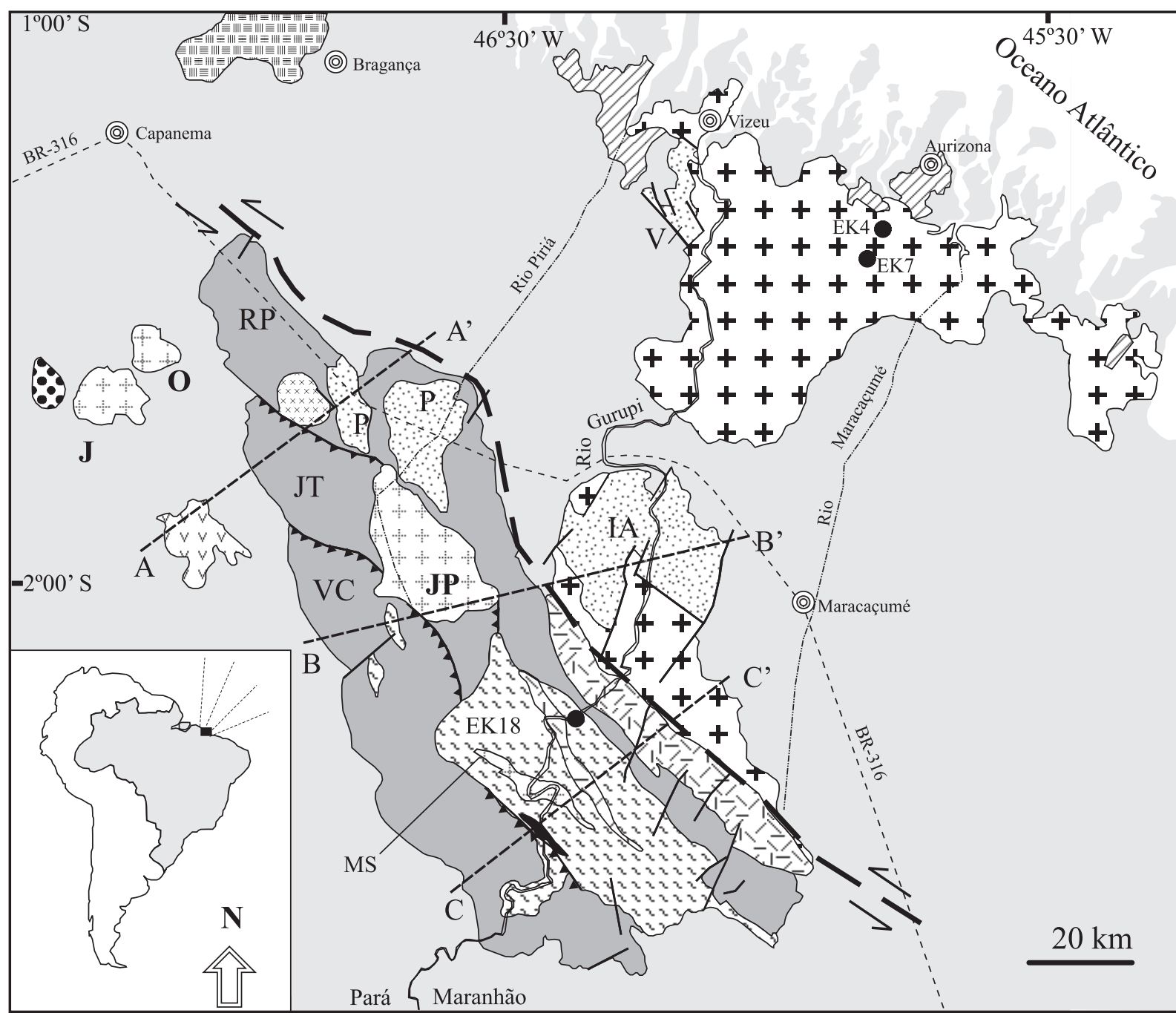

Domínio (Cráton) São Luís

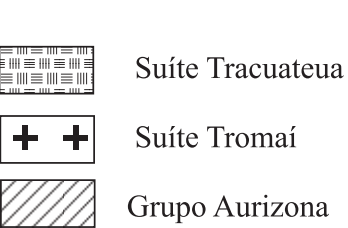

\section{Domínio (Cinturão) Gurupi}

Granito Ney Peixoto

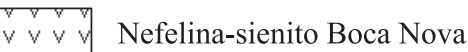

Granitóides peraluminosos

Ourém $(\mathrm{O})$, Jonasa $(\mathrm{J})$, Japiim(JP), e Maria Suprema (MS)

(1) Tonalito Itamoari

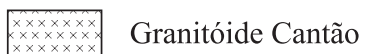

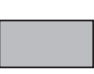

Grupo Gurupi formações Rio Piritoró RP), Jaritequara (JT), Vila Cristal (VC)

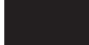

Kinzigito Marajupema

Complexo Maracaçumé

\section{Coberturas sedimentares}

Cobertura sedimentar fanerozóica

Coberturas sedimentares diversas Piriá (P), Igarapé de Areia (IA) e Vizeu (V)

$\checkmark$ Falhas de cavalgamento

$\longleftarrow$ Zona de CisalhamentoTentugal

- Localização das amostras datadas neste estudo

AA' Posição das seções geológicas (vide figura 3)

(a) Cidades / vilas

Figura 1. Mapa geológico da região do Gurupi (compilado e modificado de Pastana, 1995; Almeida, 2000; Costa, 2000). 


\section{Grupo Aurizona}

A unidade foi definida por Pastana (1995) e compreende uma seqüência metavulcano-sedimentar metamorfizada em facies xisto verde, localmente facies anfibolito, composta por xistos de naturezas diversas, filitos, quartzitos, rochas metapiroclásticas, metachert e algumas rochas metamáficas e metaultramáficas, havendo larga predominância de termos paraderivados em relação aos ortoderivados. As rochas apresentam xistosidade em geral orientada segundo $\mathrm{N} 15^{\circ}-70^{\circ} \mathrm{W}$ com mergulhos fortes para NE. Esse conjunto metavulcano-sedimentar tem sua ocorrência limitada ao domínio São Luís, correspondendo a uma parte do que era anteriormente conhecido como Grupo Gurupi (ver descrição a seguir).

Datações em rocha total (ardósia e filito) pelos métodos Rb-Sr (Cordani et al., 1984 apud Abreu, 1990) e K-Ar (Amaral, 1974 apud Abreu, 1990) apontaram, respectivamente, idades de 1820 Ma e 2054 Ma, enquanto que anfibólios de anfibolito forneceram idade K-Ar de $2360 \pm 300$ Ma (Tabelas 1 e 2). Pastana (1995), devido à ausência de dados geocronológicos mais precisos, posicionou a unidade no amplo intervalo Arqueano/Paleoproterozóico. Klein \& Moura (2001a) dataram cristais de zircão de uma rocha metapiroclástica, definindo uma idade de $2240 \pm 5$ Ma para essa unidade (Tabela 3).

\section{Suíte Intrusiva Tromaí}

Unidade de grande extensão geográfica (Figura 1), teve sua definição devida a Costa et al. (1977) que, ao conjunto vulcano-plutônico constituído por tonalitos, trondhjemitos, granodioritos (TTG), granitos, quartzo-andesitos, riolitos e dacitos, propuseram a denominação de Associação Anorogênica Tromaí. Os mesmos autores apresentaram datações pelos métodos Rb-Sr e K-Ar de, respectivamente, $2076 \pm 96$ Ma e $1945 \pm 90$ Ma (Tabelas 1 e 2). Pastana (1995) a redefiniu como Suíte Tromaí e a descreveu como consti-

Tabela 1. Principais dados geocronológicos pelo método Rb-Sr para rochas da região do Gurupi, incluindo dados deste estudo.

\begin{tabular}{|c|c|c|c|c|c|c|c|}
\hline Rocha & $\begin{array}{l}\text { Material }^{1} \\
\text { analisado }\end{array}$ & $\begin{array}{c}\text { Rb } \\
\text { (ppm) }\end{array}$ & $\begin{array}{c}\mathrm{Sr} \\
\text { (ppm) }\end{array}$ & ${ }^{87} \mathrm{Rb} /{ }^{86} \mathrm{Sr}$ & ${ }^{87} \mathrm{Sr} /{ }^{86} \mathrm{Sr}$ & $\begin{array}{r}\text { Idade } \\
(\mathrm{Ma})\end{array}$ & Referências \\
\hline \multicolumn{8}{|l|}{ Grupo Aurizona } \\
\hline ardósia & RT & 155,6 & 273,7 & 1,62 & 0,75 & 1820 & Cordani et al. $(1984)^{2}$ \\
\hline $\begin{array}{l}\text { Suíte Tromaí } \\
\text { tonalito }\end{array}$ & RT & NF & NF & NF & NF & $2076 \pm 96$ & Costa et al. (1977) \\
\hline $\begin{array}{l}\text { rocha de embasamento }{ }^{3} \\
\text { Suíte Tracuateua }\end{array}$ & RT & 38,7 & 194,5 & 0,58 & 0,72 & 1590 & Hurley et al. $(1967,1968)$ \\
\hline granitóide & RT & NF & NF & 10,01 & 0,98 & 1945 & Hurley et al. $(1967,1968)$ \\
\hline granitóide & RT & NF & NF & 8,8 & 0,95 & 1980 & Hurley et al. $(1967,1968)$ \\
\hline granitóide & RT & NF & NF & 9,35 & 0,97 & 2000 & Hurley et al. $(1967,1968)$ \\
\hline granitóide & RT & NF & NF & 17,64 & 1,21 & 2035 & Hurley et al. $(1967,1968)$ \\
\hline granitóide & RT (4) & NF & NF & NF & NF & $2047 \pm 140$ & Wanderley $\mathrm{F}^{\circ}(1980)$ \\
\hline Complexo Maracaçumé & & & & & & & \\
\hline gnaisse? & RT & 73,5 & 261,9 & 0,82 & 0,71 & 580 & Hurley et al. $(1967,1968)$ \\
\hline gnaisse? & RT & 72,2 & 150,4 & 1,41 & 0,72 & 530 & Hurley et al. $(1967,1968)$ \\
\hline gnaisse? & RT & 106,9 & 179,7 & 1,74 & 0,73 & 800 & Hurley et al. $(1967,1968)$ \\
\hline Grupo Gurupi & & & & & & & \\
\hline metaconglomerado & RT & NF & NF & 1,51 & 0,73 & $1096 \pm 104$ & Cordani et al. $(1984)^{2}$ \\
\hline metaconglomerado & matriz & 65,5 & 104,4 & 1,77 & 0,72 & $580 \pm 91$ & Cordani et al. $(1984)^{2}$ \\
\hline metaconglomerado & seixo & 47 & 171,7 & 0,8 & 0,71 & $746 \pm 192$ & Cordani et al. $(1984)^{2}$ \\
\hline $\begin{array}{l}\text { Granito Maria Suprema } \\
\text { leucogranito }\end{array}$ & mus $+F K+\mathrm{RT}^{4}$ & - & - & - & - & $1710 \pm 32$ & Klein \& Moura (2001) \\
\hline $\begin{array}{l}\text { Granitóide Jonasa } \\
\text { granodiorito } \\
\text { granodiorito }\end{array}$ & $\begin{array}{c}\mathrm{RT}(6) \\
\mathrm{bt}+\mathrm{mus}+\mathrm{FK}+\mathrm{RT}\end{array}$ & $\begin{array}{c}203-280 \\
-\end{array}$ & $\begin{array}{c}121-375 \\
-\end{array}$ & $\begin{array}{c}0,54-2,30 \\
-\end{array}$ & $\begin{array}{c}0,74-0,89 \\
-\end{array}$ & $\begin{array}{c}2018 \pm 61 \\
525 \pm 20\end{array}$ & $\begin{array}{l}\text { este estudo } \\
\text { este estudo }\end{array}$ \\
\hline $\begin{array}{l}\text { Sienito Boca Nova } \\
\text { nefelina sienito }\end{array}$ & RT (5) & $148-212$ & $146-946$ & $1,58-3,33$ & $0,71-0,74$ & $723 \pm 30$ & Villas (1982) \\
\hline $\begin{array}{l}\text { Granito Ney Peixoto } \\
\text { granitos }\end{array}$ & $\mathrm{RT}(4)$ & $243-285$ & $151-177$ & $4,05-5,48$ & $0,74-0,75$ & $580 \pm 58$ & Villas (1982) \\
\hline
\end{tabular}

1 - números entre parêntesis indicam quantidade de pontos usados no cálculo de idade isocrônica; demais idades são convencionais; 2 - citado por Abreu (1990); ${ }^{3}$ - designação constante na referência original (refere-se a tonalitos); ${ }^{4}$ - isócrona mineral; RT - rocha total; mus - muscovita; bt - biotita; FK - feldspato potássico; NF - dado não fornecido pela fonte consultada. 
Tabela 2. Principais dados geocronológicos pelo método K-Ar em rochas da região do Gurupi.

\begin{tabular}{|c|c|c|c|c|c|c|}
\hline $\begin{array}{c}\text { Unidade / } \\
\text { Rocha }\end{array}$ & $\begin{array}{c}\text { Material } \\
\text { analisado }\end{array}$ & $\% \mathrm{~K}$ & ${ }^{40} \mathrm{Ar}$ rad & $\begin{array}{c}{ }^{40} \mathrm{Ar} \text { atm } \\
(\%)\end{array}$ & $\begin{array}{l}\text { Idade } \\
(\mathrm{Ma})\end{array}$ & Referência \\
\hline \multicolumn{7}{|l|}{ Grupo Aurizona } \\
\hline anfibolito & anf & 0,599 & 12,66 & 4 & $2360 \pm 300$ & Almeida et al. (1968) \\
\hline filito & RT & 3,11 & 46,05 & 3,9 & $2054 \pm 64$ & Amaral $(1974)^{1}$ \\
\hline \multicolumn{7}{|l|}{ Suíte Tromaí } \\
\hline tonalito & RT & NF & NF & NF & $1945 \pm 90$ & Costa et al. (1977) \\
\hline \multicolumn{7}{|l|}{ Suíte Tracuateua } \\
\hline granito & mus & 9,17 & 126,06 & 0,4 & $1970 \pm 60$ & Almeida et al. (1968) \\
\hline granitóide & mus & NF & NF & NF & 1933 & Hurley et al. (1967) \\
\hline granitóide & mus & NF & NF & NF & 1910 & Hurley et al. (1967) \\
\hline granitóide & bio & NF & NF & NF & $1906 \pm 92$ & Wanderley $F^{\circ}(1980)$ \\
\hline granitóide & mus & NF & NF & NF & $2056 \pm 60$ & Wanderley $F^{\circ}(1980)$ \\
\hline \multicolumn{7}{|c|}{ Granito Ney Peixoto } \\
\hline granito & mus & 8,78 & 20,82 & 9,3 & $517 \pm 15$ & Almeida et al. (1968) \\
\hline granito & mus & $\mathrm{NF}$ & NF & NF & $544 \pm 14$ & Villas (1982) \\
\hline granito & bio & NF & NF & NF & $534 \pm 14$ & Villas (1982) \\
\hline granito & bio & NF & NF & NF & $528 \pm 17$ & Villas (1982) \\
\hline \multicolumn{7}{|l|}{ Sienito Boca Nova } \\
\hline nefelina sienito & bio & NF & NF & NF & $580 \pm 10$ & Jorge-João (1980) \\
\hline \multicolumn{7}{|c|}{ Embasamento Bacia Parnaíba } \\
\hline granito & bio & 5,52 & 17,26 & 2,7 & $666 \pm 20$ & Almeida et al. (1968) \\
\hline biotita-quartzito & bio & 6,41 & 15,72 & 1,5 & $504 \pm 15$ & Almeida et al. (1968) \\
\hline
\end{tabular}

1. citado por Abreu (1990). Anf - anfibólio; mus - muscovita; bio - biotita; RT - rocha total; NF - não fornecida pela fonte consultada.

Tabela 3. Sumário das idades obtidas por evaporação de Pb em monocristais de zircão, e das idades modelo $\mathrm{Sm}-\mathrm{Nd}\left(\mathrm{T}_{\mathrm{DM}}\right)$ disponíveis para a região do Gurupi.

\begin{tabular}{|c|c|c|c|c|}
\hline Unidade & Rocha datada & $\begin{array}{l}\text { Idade em zircão } \\
(\mathrm{Ma})\end{array}$ & $\begin{array}{c}\text { Idade modelo TDM } \\
(\mathrm{Ga})\end{array}$ & Referências \\
\hline Grupo Aurizona & metapiroclástica & $2240 \pm 5$ & ND & Klein \& Moura (2001) \\
\hline \multirow[t]{3}{*}{ Suíte Tromaí } & trondhjemito & $2165 \pm 2$ & ND & Klein \& Moura (2001) \\
\hline & tonalito & $2149 \pm 5$ & ND & Klein \& Moura (2001) \\
\hline & tonalito (Itamoari) & $2148 \pm 4$ & ND & Klein \& Moura (2001) \\
\hline Suíte Tracuateua & granitos & $2086 \pm 10$ & $2,31-2,50$ & Palheta (2001) \\
\hline Microtonalito Caxias & microtonalito & $1985 \pm 4$ & 2,17 & Klein et al. (2002) \\
\hline Complexo Maracaçumé & gnaisse tonalítico & $2135 \pm 4$ & ND & este estudo \\
\hline \multirow[t]{2}{*}{ Grupo Gurupi } & xisto (metavulcânica félsica) & $2148 \pm 1$ & ND & Klein \& Moura (2001) \\
\hline & metadacito & $2160 \pm 3$ & ND & Klein \& Moura (2001) \\
\hline Granitóide Cantão & monzogranito & $2159 \pm 13$ & $2,21-2,48$ & Palheta (2001) \\
\hline Granito Ney Peixoto & granito & $549 \pm 4$ & 1,7 & Palheta (2001) \\
\hline
\end{tabular}

ND - dado inexistente ou não disponível. 
tuída por intrusões granitóides polifásicas e de dimensões batolíticas, restritas ao domínio São Luís, incorporando, além das rochas da Associação Anorogênica Tromaí original, parte do que era anteriormente considerado Complexo Maracaçumé (ver descrição abaixo).

Os TTG são tanto equigranulares como porfiríticos e apresentam texturas e mineralogia ígneas bem preservadas, a despeito de transformações hidrotermais e/ou metamórficas posteriores. Enclaves microgranulares máficos são relativamente abundantes e apresentam dimensões centimétricas a decimétricas. Alguns granitóides apresentam deformação tectônica manifestada na forma de foliação (texturas nematoblástica e lepidoblástica) ou milonitização localizada, quando cortados por zonas de cisalhamento de pequeno porte. Outros granitóides não apresentam trama tectônica evidente. Nas proximidades da Zona de Cisalhamento Tentugal tornam-se fortemente miloníticos, o que levou Pastana (1995) a considerar essa porção muito deformada e aflorante no domínio Gurupi como outra unidade (Tonalito Itamoari). Visto que a única diferença é o grau de deformação, essas rochas são, neste trabalho, consideradas como parte da Suíte Tromaí.

Os granitóides Tromaí são cálcico-alcalinos e metaluminosos, tipo I, com padrões de ETR e elementos traço (LILE, HFSE) comparáveis aos de granitóides relacionados a arcos vulcânicos e zonas de subducção e/ou ambientes pós-colisionais de orogêneses fanerozóicas. Dados geocronológicos em zircão, obtidos por Klein \& Moura (2001a), mostram idades de cristalização entre $2148 \pm 4$ Ma e $2165 \pm 2$ Ma para esses granitóides (Tabela 3).

A subunidade Granito Areal (Figura 2) é constituída por sienogranitos e monzogranitos e foi considerada por Pastana (1995) como gerada pela fusão das rochas tonalíticas da Suíte Tromaí. Ressalta-se que neste caso a utilização da designação suíte é imprópria, pois ela requer cogeneticidade. Possuem coloração rosada, e são em geral inequigranulares a porfiríticos. Não possuem trama tectônica, exceto quando cortados por zonas de cisalhamento discretas, e apresentam enclaves de rochas metavulcano-sedimentares com dimensões métricas a decamétricas. Possuem caráter peraluminoso, são mais evoluídos, com maior fracionamento de ETR leves em relação aos pesados e apresentam anomalia negativa de Eu mais pronunciada, assinatura mais próxima a de granitóides sincolisionais (continente-arco). Uma amostra de monzogranito (EK4), coletada no leito do rio Tromaí, e outra de um sienogranito (EK7), coletado próximo à vila do Areal, que empresta o nome à unidade (Figura 2), foram utilizadas para datação. Da amostra EK4, apenas um cristal de zircão produziu resultado, de boa qualidade analítica (erro pequeno, alta razão ${ }^{206} \mathrm{~Pb} /{ }^{204} \mathrm{~Pb}$ ), fornecendo idade de $2152 \pm 3$ Ma (Tabela 4). Da amostra EK7 cinco cristais prismáticos, de aspecto ígneo, forneceram uma idade média de $2149 \pm 4$ Ma (Tabela 4.). As duas idades se superpõem dentro dos limites de erro analítico e são interpretadas como a idade mínima de cristalização do granitóide.

Com base nas características descritas acima e, especialmente na contemporaneidade entre o Granito Areal e os tonalitos Tromaí, a hipótese de formação do primeiro a partir de fusão do segundo, conforme sugestão de Pastana (1995), não se sustenta. Neste caso, outras duas hipóteses podem ser consideradas:

1. o granito Areal é uma fase mais evoluída do magmatismo Tromaí, de forma que a designação de suíte intrusiva seja aplicável;

2. trata-se de magmatismo contemporâneo, mas distinto, o que exigiria o desmembramento do Granito Areal da Suíte Intrusiva Tromaí e sua redefinição como uma unidade a parte. Mais estudos (p. ex., geoquímica, Sm-Nd) são necessários para a resolução dessa questão e, na falta destes, é mantida a designação Tromaí para englobar os tonalitos, trondhjemitos e granodioritos, além do Granito Areal, acrescida da adjetivação “intrusiva” (Suíte Intrusiva Tromaí).

\section{Suíte Intrusiva Tracuateua}

Essa designação é devida à Costa (2000) que reuniu nessa suíte os corpos granitóides de Tracuateua, Mirasselvas e Tauari, aflorantes na porção noroeste da área, próximo à cidade de Bragança (Figura 1). São rochas isotrópicas a foliadas, com biotita e muscovita e portam enclaves de xistos e migmatitos (Lowell, 1985). As características petrográficas e geoquímicas dessas rochas foram consideradas compatíveis com as de granitóides tipo S, peraluminosos, derivados de fusão de rochas crustais (meta) sedimentares (Lowell, 1985; Costa, 2000). Datações Rb-Sr (convencionais e isocrônicas) em rocha total e K-Ar em muscovita e anfibólio (Hurley et al., 1967; Wanderley $\mathrm{F}^{\circ}$, 1980) situam-se no intervalo 1906 e $2056 \mathrm{Ma}$ (Tabelas 1 e 2). Palheta (2001) determinou idades de cristalização entre 2086 e 2091 Ma em zircão e idades modelo Sm-Nd ( $\left.\mathrm{T}_{\mathrm{DM}}\right)$ entre 2,31 e 2,50 Ga (Tabela 3), com valores de $\varepsilon_{\mathrm{Nd}}(\mathrm{t})$ entre $+1,15 \mathrm{e}-1,33$.

\section{Microtonalito Caxias}

Consiste em pequeno corpo intrusivo que hospeda a mineralização aurífera no garimpo do Caxias (Figura 2). É constituído por uma rocha de granulação fina e equigranular, de composição tonalítica, isotrópica a orientada nas proximidades de zonas de cisalhamento, mostrando-se 
Tabela 4. Dados isotópicos obtidos por evaporação de Pb em monocristais de zircão para o Granito Areal e em gnaisse e mobilizado leucogranítico do Complexo Maracaçumé. Interpretações no texto.

\begin{tabular}{|c|c|c|c|c|c|c|c|c|c|c|}
\hline Zircão & $\begin{array}{c}\text { T evap } \\
\left({ }^{\circ} \mathrm{C}\right)\end{array}$ & $\begin{array}{l}\mathbf{N}^{\circ} \text { de } \\
\text { razões }\end{array}$ & $\begin{array}{l}{ }^{206} \mathrm{~Pb} / \\
{ }^{204} \mathrm{~Pb}\end{array}$ & $\begin{array}{l}{ }^{208} \mathrm{~Pb} / \\
{ }^{206} \mathrm{~Pb}\end{array}$ & $2 \sigma$ & $\begin{array}{c}{ }^{207} \mathrm{~Pb} / \\
{ }^{206} \mathrm{~Pb}^{(\mathrm{C})}\end{array}$ & $2 \sigma$ & $\begin{array}{c}\text { idade da etapa } \\
(\mathrm{Ma})\end{array}$ & $2 \sigma$ & $\begin{array}{c}\text { idade média } \\
(\mathrm{Ma})\end{array}$ \\
\hline \multicolumn{11}{|c|}{ Granito Areal } \\
\hline 12 & 1500 & $84 / 84$ & $>10000$ & 0,12699 & 0,00035 & 0,13404 & 0,00021 & 2152 & 3 & $2152 \pm 3$ \\
\hline \multicolumn{11}{|c|}{ EK7 - sienogranito } \\
\hline \multirow[t]{2}{*}{5} & 1500 & $88 / 88$ & $>10000$ & 0.11623 & 0.00030 & 0.13332 & 0.00026 & 2142 & 3 & \\
\hline & 1550 & $70 / 70$ & $>10000$ & 0.11722 & 0.00068 & 0.13399 & 0.00094 & 2151 & 12 & \\
\hline 9 & 1500 & $88 / 88$ & $>10000$ & 0.09679 & 0.00099 & 0.13408 & 0.00020 & 2152 & 3 & \\
\hline 10 & 1500 & $70 / 70$ & $>10000$ & 0.11325 & 0.00081 & 0.13369 & 0.00021 & 2147 & 3 & \\
\hline 11 & 1500 & $18 / 18$ & 6451 & 0.15443 & 0.00117 & 0.13368 & 0.00072 & 2147 & 8 & \\
\hline 14 & 1500 & $80 / 80$ & 9434 & 0.11905 & 0.00389 & 0.13416 & 0.00028 & 2153 & 4 & $2149 \pm 4$ \\
\hline \multicolumn{11}{|c|}{$\begin{array}{l}\text { Complexo Maracaçumé } \\
\text { EK18A - Gnaisse Tonalítico }\end{array}$} \\
\hline 2 & 1500 & $8 / 8$ & 3817 & 0,0802 & 0,00106 & 0,132 & 0,0019 & 2125 & 25 & \\
\hline 14 & 1500 & $38 / 38$ & 9708 & 0,17224 & 0,00088 & 0,13278 & 0,00031 & 2135 & 4 & \\
\hline 15 & 1500 & $20 / 20$ & 3690 & 0,15288 & 0,00104 & 0,1311 & 0,00109 & 2113 & 15 & \\
\hline \multicolumn{11}{|c|}{ EK18B - mobilizado leucogranítico } \\
\hline 6 & 1450 & $4 / 4$ & $>10000$ & 0,00946 & 0,00136 & 0,128 & 0,0027 & 2071 & 37 & \\
\hline \multirow[t]{3}{*}{9} & 1500 & $24 / 24$ & $>10000$ & 0,01127 & 0,00016 & 0,12742 & 0,00043 & 2063 & 6 & \\
\hline & 1550 & $16 / 16$ & $>10000$ & 0,01134 & 0,00019 & 0,1322 & 0,00123 & 2128 & 16 & \\
\hline & 1580 & $8 / 8$ & $>10000$ & 0,01114 & 0,00006 & 0,12957 & 0,00147 & 2092 & 20 & \\
\hline 2 & 1500 & $14 / 14$ & $>10000$ & 0,1947 & 0,00229 & 0,17504 & 0,0012 & 2607 & 11 & \\
\hline \multirow[t]{2}{*}{13} & 1450 & $8 / 8$ & 2577 & 0,20459 & 0,00115 & 0,16507 & 0,00047 & 2509 & 5 & \\
\hline & 1500 & $28 / 28$ & 9523 & 0,19927 & 0,00131 & 0,17229 & 0,0004 & 2580 & 4 & \\
\hline
\end{tabular}

(c) razão corrigida segundo modelo de Stacey \& Kramers (1975).

hidrotermalizada em larga escala. Apresenta idade em zircão de $1985 \pm 4$ Ma e idade modelo Sm-Nd $\left(\mathrm{T}_{\mathrm{DM}}\right)$ de 2,17 Ga, com $\varepsilon_{\mathrm{Nd}}(\mathrm{t}) \mathrm{de}+0,74$ (Klein et al., 2002) (Tabela 3).

\section{Complexo Maracaçumé}

Foi originalmente definido por Costa et al. (1977) como Associação Metamórfica Maracaçumé, contendo gnaisses e migmatitos de composição granítica a tonalítica portadores de enclaves anfibolíticos, ocorrendo tanto no domínio São Luís quanto no domínio Gurupi. Abreu et al. (1980) renomearam a unidade para Complexo Maracaçumé e a posicionaram no Arqueano. A concepção atual do complexo é devida a Pastana (1995), que limitou sua ocorrência ao domínio Gurupi (Figura 1). Segundo aquele autor, essa unidade representa porções mais basais da crosta, aflorando em contato tectônico com as demais unidades do domínio (Figura 3). A constituição litológica do complexo é dominada por ortognaisses de composição tonalítica, trondhjemítica e granodiorítica, além de paragnaisses, mostrando efeitos variados de migmatização, tendo suas rochas atingido condições metamórficas de facies anfibolito médio a alto.

Dados Rb-Sr em rocha total (Hurley et al., 1968) acusaram idades entre $580 \mathrm{Ma}$ e $800 \mathrm{Ma}$ (Tabela 1). Entretanto,
Pastana (1995) manteve o posicionamento dessa unidade no Arqueano, unicamente por correlação com outras unidades do Cráton Amazônico (p. ex. Complexo Xingu).

Duas amostras, coletadas ao longo do rio Gurupi (Figura 1), foram datadas por evaporação de $\mathrm{Pb}$ em zircão (Tabela 4). A amostra EK18A é um gnaisse tonalítico de granulação média, bandado e dobrado, apresentando mobilizados leucograníticos de granulação grossa (EK18B). Na amostra EK18A, três cristais de zircão forneceram idades entre $2113 \mathrm{Ma}$ e $2135 \mathrm{Ma}$. Quatro cristais de zircão da amostra EK18B mostram dois grupos distintos de idades. Dois cristais forneceram idades entre 2063 Ma e 2128 Ma, próximas às apresentadas pela amostra EK18A, e dois cristais apresentaram idades de $2580 \mathrm{Ma}$ e $2607 \mathrm{Ma}$, interpretadas como herança (vide discussão dos dados mais adiante).

\section{Kinzigito Marajupema}

Pastana (1995) reuniu quartzitos feldspáticos portadores de cordierita, granada, muscovita, biotita e plagioclásio, associados a muscovita-quartzitos, na unidade Kinzigito Marajupema, restrita ao domínio Gurupi, ocorrendo próximo ao contato entre o Complexo Maracaçumé e o Grupo Gurupi (Figura 1). Aquele autor atribuiu condições de 


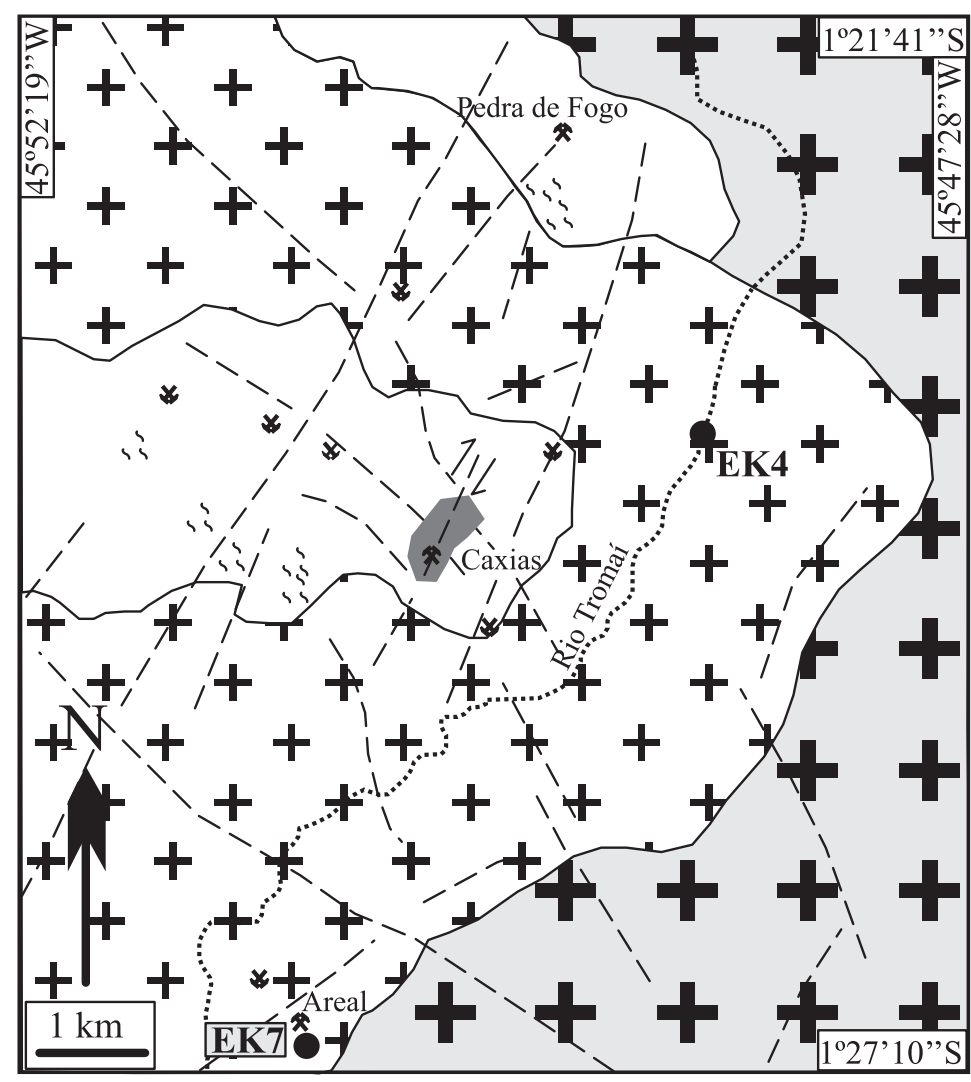

25uíte Tromaí

†ranito Areal

Microtonalito Caxias

Grupo Aurizona

_- falha, zona de cisalhamento

$\because \quad$ Foliações

* Ouro primário

* Ouro secundário

Amostras datadas neste estudo

Figura 2. Mapa geológico da porção central-norte do domínio São Luís, em área de afloramento do Granito Areal e do Microtonalito Caxias. Adaptado de Klein et al. (2002).

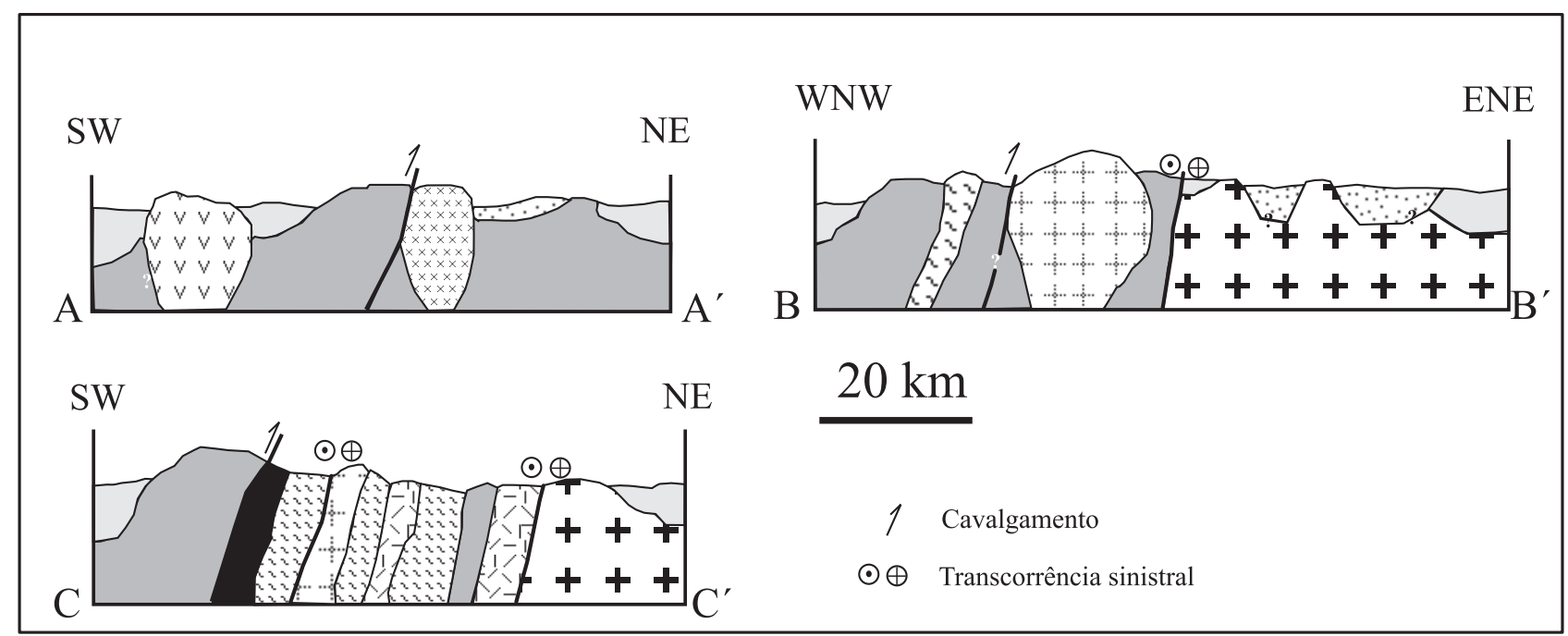

Figura 3. Seções geológicas esquemáticas (sem escala vertical), mostrando possíveis relações entre as diversas unidades geológicas da região do Gurupi. Posição das seções e símbolos das unidades como na Figura 1. 
metamorfismo granulítico para essas rochas. Contudo, a ausência de feldspato alcalino e sillimanita e a abundância de muscovita sugerem que as rochas não atingiram facies granulito, mas, no máximo, anfibolito alto. O seu posicionamento no contato entre rochas metassedimentares do Grupo Gurupi e gnaisses do Complexo Maracaçumé pode ser sugestiva de tratar-se de lentes de quartzito de facies anfibolito associadas a uma dessas unidades, sem a necessidade de representar uma unidade autônoma. A unidade foi posicionada, em sua definição, no Arqueano, mas dados preliminares em zircão (Klein \& Moura, 2001b) descartam essa possibilidade, sendo a unidade provavelmente de idade paleoproterozóica.

\section{Grupo Gurupi}

Similarmente ao Grupo Aurizona, é constituído por um conjunto metavulcano-sedimentar metamorfizado em facies xisto verde, localmente anfibolito. Foi definido por Francisco et al. (1971) que se referiram a rochas que ocorriam tanto no domínio São Luís quanto no Gurupi. É, possivelmente, a unidade mais polêmica, tendo passado por diversas reinterpretações no que se refere à sua denominação, conteúdo litológico, litoestratigrafia, idade e distribuição geográfica. Sua atual conceituação é devida a Pastana (1995), que restringiu sua ocorrência ao domínio Gurupi (Figura 1). Costa (2000) descreveu um zonamento litológico, sedimentar e metamórfico nas rochas desse grupo aflorantes ao longo do rio Piriá e propôs sua subdivisão em três formações, de nordeste para sudoeste (Figura 1): Rio Piritoró (sequiência pelítico-carbonosa-fosforítica de águas não muito rasas, e grau metamórfico muito baixo a anquimetamórfico); Jaritequara (seqüência pelítica metamorfizada até xisto verde alto); e Vila Cristal, composta por xistos feldspáticos bandados, contendo granada, cloritóide e estaurolita, metamorfizados em facies epidoto-anfibolito a anfibolito. Essa subdivisão não se verifica no perfil do rio Gurupi. Além disso, o conteúdo vulcânico tem sido subestimado especialmente na Formação Rio Piritoró, onde rochas metavulcânicas félsicas, intermediárias e máficas, associadas com rochas tufáceas, ocorrem intercaladas com rochas metassedimentares, constituindo importantes hospedeiras de mineralizações auríferas, como Cachoeira, Chega Tudo e Montes Áureos (Bettencourt et al., 1991; Yamaguti \& Villas, 1999; Torresini, 2000). As relações de contato com outras unidades também são pouco visíveis, tendo sido determinadas relações de intrusão com os granitóides Japiim e Cantão e por falhamento normal com a Formação Piriá (cobertura sedimentar) (Costa, 2000). Entende-se, portanto, que essa unidade ainda requer estudos (mapeamento, geoquímica, metamorfismo) e que uma redefinição quanto ao conteúdo litológico e conceito, pelo menos da Formação Rio Piritoró, se faz necessária.

Para esta unidade foi também atribuída idade Arqueana a Paleoproterozóica (Pastana, 1995), embora as datações $\mathrm{Rb}-\mathrm{Sr}$ disponíveis mostrem idades entre 530 e $1096 \mathrm{Ma}$ (Hurley et al., 1968; Cordani et al., 1984 apud Abreu, 1990). Klein \& Moura (2001a) apresentaram dados em zircão de duas amostras de rochas metavulcânicas félsicas que ocorrem intercaladas com rochas metassedimentares. As idades médias obtidas foram $2148 \pm 1$ Ma e $2160 \pm 3$ Ma (Tabela 3), enquanto as idades de etapas individuais de evaporação variaram, respectivamente, entre 2143 e $2153 \mathrm{Ma}$, e entre 2152 e 2165 Ma. Essas idades médias e os intervalos de variação são similares aos encontrados para a Suíte Intrusiva Tromaí.

\section{Granito Maria Suprema}

Unidade definida por Pastana (1995), corresponde a um único corpo alongado de leucogranito composto por quartzo, feldspatos, biotita e muscovita, além de zircão, apatita e ocasional andaluzita. Encontra-se milonitizado, com aspecto xistoso a gnáissico, e ocorre de forma intercalada nas rochas do Complexo Maracaçumé (Figuras 1 e 3). A unidade foi interpretada por aquele autor como sendo um granitóide estratóide sincolisional (peraluminoso, tipo S), gerado por fusão parcial de rochas do Complexo Maracaçumé (embora admita, ao mesmo tempo, paraderivação) durante a implantação do Cinturão Gurupi. Em campo, a separação dessas rochas daquelas do Complexo Maracaçumé é extremamente difícil, visto que se encontram paralelizadas e misturadas devido à transposição por intenso cisalhamento transcorrente. Não há elementos suficientes para descartar a existência dessa unidade, sendo requeridos estudos mais detalhados. Entretanto, coloca-se aqui a hipótese de que essas rochas possam representar volumes importantes de mobilizados migmatíticos do Complexo Maracaçumé, ou mesmo xistos de granulação grossa intercalados nesse complexo.

Sem dado geocronológico disponível, a unidade foi posicionada no Paleoproterozóico na sua definição (Pastana, 1995) e no Neoproterozóico por Costa (2000) e Palheta (2001), por correlação com outro granitóide peraluminoso desse período (Ney Peixoto, ver abaixo). Uma isócrona mineral $\mathrm{Rb}-\mathrm{Sr}$ (muscovita + feldspato potássico + rocha total) (Klein $\&$ Moura, 2001a), acusou idade de $1710 \pm 32 \mathrm{Ma}$ (MSWD $=0,02$ ), que reflete a abertura parcial do sistema isotópico. Tomada como uma idade mínima, mostra que a unidade teria posicionamento estratigráfico pelo menos no Paleoproterozóico. 


\section{Granitóides peraluminosos 0 urém, Jonasa e Japiim}

Uma série de granitóides (Ney Peixoto, Ourém, Jonasa, Japiim e Cantão) de forma subarredondada a irregular ocorre no domínio Gurupi ou como janelas erosivas em meio à cobertura sedimentar fanerozóica (Figura 1). Alguns desses corpos foram originalmente reconhecidos por Villas (1982) e posicionados no Neoproterozóico, devido a uma datação isocrônica $\mathrm{Rb}-\mathrm{Sr}$ em rocha total que aquele autor obteve para o Granito Ney Peixoto, apontando idade de $580 \pm 58 \mathrm{Ma}$. Hasui et al. (1984) reuniram esses corpos na Suíte Granitóide Brasiliana, designação que foi modificada para Suíte Intrusiva Brasiliana por Costa (2000), que interpretou os granitóides como colisionais, relacionados ao ciclo orogênico Brasiliano. Contudo, Palheta (2001), usando datações em zircão e Sm-Nd em rocha total, demonstrou que apenas o Granito Ney Peixoto é Neoproterozóico. Os demais são Paleoproterozóicos.

Os granitóides Ourém, Jonasa e Japiim são portadores de biotita e muscovita. A composição é variada, sendo o corpo Ourém formado por granitos, Jonasa por monzogranitos e granodioritos, e Japiim por leucosienogranitos a granodioritos, portadores de enclaves microgranulares bandados com duas micas e, às vezes, com granada (Costa, 2000). Apresentam-se foliados segundo NNW-SSE, com mergulhos altos para WSW, indicando a influência de transcorrência oblíqua (Palheta, 2001). Os corpos Ourém e Jonasa estão recobertos por sedimentação fanerozóica e relações de contato só puderam ser estabelecidas para o granitóide Japiim. Costa (2000) aponta que o contato entre este granitóide e as rochas metassedimentares do Grupo Gurupi se dá tanto através de zona de cisalhamento contracional como de forma intrusiva (Figura 3), com diques sinplutônicos cortando as rochas metassedimentares encaixantes.

Palheta (2001) determinou idades em zircão entre 2061 e 2084 Ma para esses três corpos e reconheceu também populações de cristais herdados de zircão, com idades entre 2325 e 2459 Ma. Além disso, determinou idades modelo Sm-Nd entre 2,09 e 3,23 Ga, com valores de $\varepsilon_{\text {Nd }}(t)$ levemente positivos a levemente negativos (Tabela 3). Esses dados, aliados à assinatura dos granitóides e à presença de enclaves de rochas supracrustais sugerem que tenham derivado, pelo menos em parte, da fusão de protólitos crustais.

$\mathrm{O}$ estudo $\mathrm{Rb}-\mathrm{Sr}$ para o granitóide Jonasa mostra idade isocrônica em rocha total de $2018 \pm 61 \mathrm{Ma}(\mathrm{MSWD}=1,91)$ (Figura 4A, Tabela 5), enquanto a isócrona mineral definiu idade de $525 \pm 20$ Ma (Figura 4B, Tabela 6) (ver discussão adiante).

Tabela 5. Resultados das análises isotópicas $\mathrm{Rb}-\mathrm{Sr}$ em rocha total, do Granitóide Jonasa. USD = 1,38; MSWD $=1,91$. Incertezas fornecidas em $1 \sigma$, com multiplicação pelo USD. Concentrações de Rb e Sr em ppm.

\begin{tabular}{rccccccc}
\hline Amostra & $\mathbf{R b}$ & $\mathbf{S r}$ & $\mathbf{R b} / \mathbf{S r}$ & ${ }^{87} \mathbf{R b} /{ }^{86} \mathbf{S r}$ & $\sigma$ & ${ }^{87} \mathbf{S r} /{ }^{86} \mathbf{S r}$ & $\sigma$ \\
\hline 99TAG-01 & 258 & 297 & 0,87 & 2,530 & 0,048 & 0,780323 & 0,000163 \\
99TAG-02 & 273 & 328 & 0,83 & 2,420 & 0,048 & 0,772821 & 0,000037 \\
99TAG-03 & 203 & 375 & 0,54 & 1,577 & 0,026 & 0,748942 & 0,000066 \\
99TAG-04 & 280 & 325 & 0,86 & 2,509 & 0,064 & 0,774836 & 0,000076 \\
99TAG-05 & 278 & 121 & 2,30 & 6,784 & 0,127 & 0,897803 & 0,000079 \\
99TAG-06 & 267 & 295 & 0,91 & 2,641 & 0,047 & 0,780319 & 0,000161 \\
\hline
\end{tabular}

Tabela 6. Resultados das análises isotópicas $\mathrm{Rb}-\mathrm{Sr}$ em minerais e rocha total, na amostra TAG 2 do Granitóide Jonasa. USD $=2,65 ;$ MSWD = 7,01; incertezas fornecidas em 1 $\sigma$, com multiplicação pelo USD; concentrações de Rb e Sr em ppm; Bt - biotita; Mus - muscovita; Fd - feldspato; RT - rocha total.

\begin{tabular}{ccrrrrrc}
\hline $\begin{array}{c}\text { Material } \\
\text { Analisado }\end{array}$ & $\mathbf{R b}$ & \multicolumn{1}{c}{$\mathbf{S r}$} & $\mathbf{R b} / \mathbf{S r}$ & ${ }^{\mathbf{8 7}} \mathbf{R b} /{ }^{86} \mathbf{S r}$ & $\sigma$ & ${ }^{87} \mathbf{S r} /{ }^{86} \mathbf{S r}$ & $\sigma$ \\
\hline Bt & 1679 & 8,0 & 209,09 & 1032,902 & 24,499 & 7,934942 & 0,009900 \\
Mus & 905 & 24,7 & 36,64 & 115,841 & 2,188 & 1,658506 & 0,001207 \\
Fd & 183 & 470,0 & 0,39 & 1,135 & 0,021 & 0,763266 & 0,000123 \\
RT & 273 & 328,0 & 0,83 & 2,420 & 0,048 & 0,772821 & 0,000037 \\
\hline
\end{tabular}



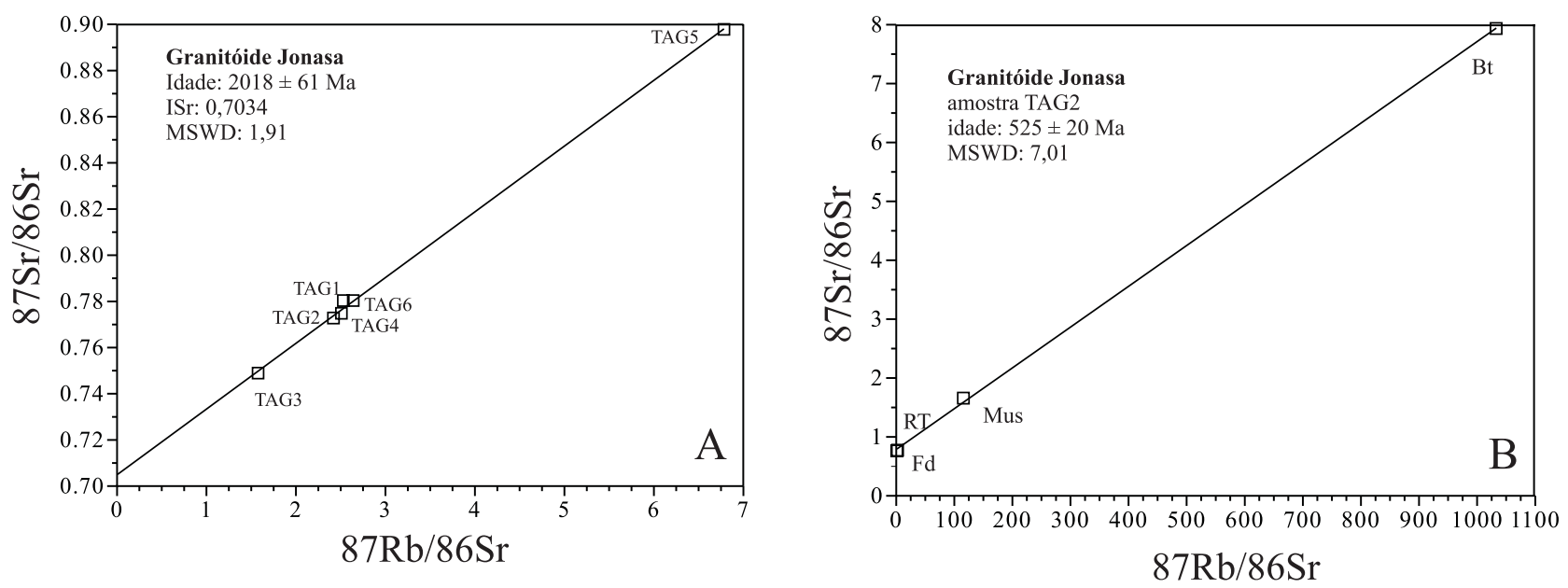

Figura 4. A - Diagrama isocrônico Rb-Sr (rocha total) com amostras do Granitóide Jonasa; B - Isócrona interna (minerais + rocha total) para a amostra TAG 2 do Granitóide Jonasa.

\section{Granitóide Cantão}

O granitóide Cantão ocorre circunscrito entre rochas do Grupo Gurupi (Figura 1) e era considerado representante da suíte Brasiliana. É um biotita-monzogranito desprovido de mica branca primária. Apresenta pouca deformação e possui enclaves de rochas similares àquelas do Grupo Gurupi (Costa, 2000; Palheta, 2001). Outras relações de contato não foram estabelecidas, mas sua forma de ocorrência e a presença de enclaves das rochas encaixantes são sugestivas de intrusão. Palheta (2001) obteve idade, em zircão, de $2159 \pm 13$ Ma e idade modelo $\mathrm{T}_{\mathrm{DM}}$ entre 2,21 e 2,48 Ga, com $\varepsilon_{N d}(t)$ levemente negativo.

Esses dados demonstram que o granitóide Cantão é petrográfica, composicional, estrutural e cronologicamente distinto daqueles granitóides peraluminosos, aos quais era relacionado. Observa-se que essas características, incluindo idade, são sugestivamente similares às descritas para o Granito Areal.

\section{Nefelina Sienito-G naisse Boca Nova}

Foi reconhecido inicialmente por Jorge-João (1980) como Litchfieldito Boca Nova e sua designação atual é devida a Costa (2000). Constitui-se em um corpo de forma irregular, recoberto por sedimentação fanerozóica (Figura 1) que impede a visualização das relações de contato com as rochas encaixantes. É uma intrusão alcalina sienítica metamorfizada e deformada, apresentando estrutura gnáissica e migmatização restrita. Petrograficamente é constituído por albita, feldspato alcalino, nefelina e biotita, além de acessórios (Villas, 1982; Costa, 2000).

Jorge-João (1980) reportou idade K-Ar (biotita) de $580 \pm 10 \mathrm{Ma}$, enquanto Villas (1982) obteve idade isocrônica $\mathrm{Rb}-\mathrm{Sr}$ em rocha total de $723 \pm 30 \mathrm{Ma}$, que interpretou como idade de rejuvenescimento de intrusão anorogênica. Diante disto, esta unidade tem sido posicionada tanto no Neoproterozóico como no Mesoproterozóico (Abreu et al., 1980; Costa, 2000).

\section{Granito Ney Peixoto}

O Granito Ney Peixoto tem sido considerado integrante da suíte Brasiliana, baseado em idade isocrônica $\mathrm{Rb}-\mathrm{Sr}$ em rocha total de $580 \pm 58 \mathrm{Ma}\left({ }^{87} \mathrm{Sr} /{ }^{86} \mathrm{Sr}_{\mathrm{i}}=0,704\right)$ determinada por Villas (1982). De fato, até o momento, é a única unidade formada no Neoproterozóico, o que foi comprovado pela idade em zircão de $549 \pm 4 \mathrm{Ma}$ (Palheta, 2001). Esse mesmo autor determinou idades modelo $\mathrm{Sm}-\mathrm{Nd}$ em torno de 1,70 Ga, com valores de $\varepsilon_{\mathrm{Nd}}(\mathrm{t})$ em torno de -8 . Consiste em um único corpo recoberto por sedimentos fanerozóicos, sem relações de contato visíveis com suas rochas encaixantes. Dada a sua posição geográfica (Figura 1) e idade é provável que seja intrusivo nas rochas do Grupo Gurupi.

Descrições de Costa (2000), Palheta (2001) e Villas (2001) mostram que constitui-se de granitos com duas micas, de granulação dominantemente média, podendo apresentar porções pegmatóides e são foliados segundo NNW-SSE. Características químicas apresentadas por Villas (2001) mostram assinatura peraluminosa, com padrões de terras raras 
moderadamente fracionadas e com forte anomalia negativa de Eu. Utilizando as características mineralógicas, químicas e isotópicas, além do contexto geológico e geocronologia, Villas (2001) admite mistura de fontes sedimentares e ígneas para o magma gerador do Granito Ney Peixoto e sugere ambiente de colisão continental para a sua colocação.

\section{Coberturas sedimentares diversas}

Reunidas sob a denominação genérica de coberturas sedimentares diversas (Figura 1), as formações Igarapé de Areia, Viseu e Piriá, interpretadas como bacias molássicas (Abreu et al., 1980), constituem-se em depósitos continentais de clima semi-árido (arenitos arcoseanos, pelitos e conglomerados), com pacotes dobrados e foliados, localmente anquimetamorfizados. Seu posicionamento estratigráfico tem variado largamente, do Proterozóico ao Eopaleozóico, em função das diferentes concepções evolutivas adotadas para a região (Abreu et al., 1980; Pastana, 1995; Costa, 2000). Cobrindo toda a região (Figura 1) ocorrem extensas bacias sedimentares fanerozóicas, intracratônicas ou de margem continental passiva.

\section{DISCUSSÃO DOS NOVOS DADOS GEOCRONOLÓGICOS}

As idades obtidas pelo método de evaporação de $\mathrm{Pb}$ em monocristais de zircão são consideradas idades mínimas, visto que não é possível avaliar o grau de discordância das mesmas. Entretanto, estudos comparativos mostram que essas idades costumam ser próximas às obtidas pelo método U-Pb convencional ou SHRIMP (Kober, 1986; Ansdell \& Kyser, 1991; Söderlund, 1996). Nos procedimentos de análise aqui adotados, somente foram consideradas para cálculo de idade (de bloco ou etapa) aquelas análises com razões ${ }^{206} \mathrm{~Pb} /{ }^{204} \mathrm{~Pb}$ maiores do que 2500 .

No caso do Granito Areal, as idades de etapas de evaporação se repetem, dentro dos limites do erro analítico, em diferentes cristais de zircão. Dessa forma, uma idade média pode ser calculada $(2149 \pm 4 \mathrm{Ma}$, similar à obtida para a outra amostra do mesmo granitóide) e é interpretada como a idade mínima de cristalização do granitóide.

Nas amostras do Complexo Maracaçumé, uma ampla variação de idades foi obtida, com pouca reprodutibilidade entre as etapas de evaporação dos diferentes cristais, de forma que o cálculo de uma idade média não tem significado. A idade obtida para o zircão 14 (2135 \pm 4 Ma) é a de melhor qualidade e menor erro analítico, sendo interpretada como a idade mínima da cristalização do protólito do gnaisse.
As idades menores podem representar perda de $\mathrm{Pb}$ radiogênico (p. ex., Vanderhaeghe et al., 1998), cujo significado (se geológico ou não) é ainda desconhecido. No que concerne ao mobilizado leucogranítico, também foram obtidas idades variadas, que não permitem o cálculo de uma idade média. As idades arqueanas são interpretadas como reflexo de uma fonte mais antiga, enquanto que as idades paleoproterozóicas podem estar refletindo tanto uma fonte dessa idade como a própria cristalização do leucogranito. A ocorrência de uma idade algo menor em temperatura mais alta (amostra EK18B, zircão 9) precisa ainda ser investigada, não existindo discussão sobre o caso na literatura sobre o método aqui empregado. Questões analíticas (improvável) ou relativas à estrutura (não uniforme) dos cristais podem estar envolvidas.

Com relação aos dados $\mathrm{Rb}-\mathrm{Sr}$ do granitóide Jonasa, o resultado em rocha total é compatível com a idade de cristalização obtida anteriormente em zircão. Apesar do caráter peraluminoso, que denuncia a participação importante de materiais crustais na geração desse granitóide, a razão ${ }^{87} \mathrm{Sr} /$ ${ }^{86} \mathrm{Sr}$ inicial, de 0,7034 , é relativamente baixa e aproxima-se de valores mantélicos, o que sugere que protólitos ígneos não muito mais velhos constituíram parte do magma que gerou o granitóide Jonasa. Já a isócrona mineral demonstra efeitos termais no Neoproterozóico (metamorfismo?, deformação?) que não afetaram o sistema na escala da rocha.

\section{CONSIDERAÇÕES FINAIS E MODELO GEOTECTÔNICO PRELIMINAR}

Os recentes resultados geocronológicos obtidos em zircão, aqui complementados com novos dados relativos ao Complexo Maracaçumé e Granito Areal, fizeram com que a maioria das unidades regional passasse a contar com pelo menos uma informação geocronológica mais precisa e permitiram avanço significativo no que concerne a litoestratigrafia da região do Gurupi (previamente baseada nas sistemáticas $\mathrm{Rb}$-Sr e K-Ar). Esses resultados mostram também que o intervalo de tempo entre $2240 \mathrm{Ma} \mathrm{e} 2011 \mathrm{Ma}$ é o mais importante em termos litogênese. Não foram reconhecidas, até o momento, rochas arqueanas aflorantes na região, sendo esse Eon identificado apenas como vestígios, com base em cristais herdados de zircão e de algumas idades modelo Sm-Nd $\left(\mathrm{T}_{\mathrm{DM}}\right)$. Da mesma forma, rochas mais jovens do que $\sim 2,0$ Ga são muito limitadas, sendo comprovado até o momento somente o Granito Ney Peixoto (549 Ma) e, possivelmente, a rocha alcalina de Boca Nova (723 Ma, isócrona $\mathrm{Rb}-\mathrm{Sr}$ ).

As sistemáticas Rb-Sr e K-Ar, entretanto, mostram uma clara divisão, com uma área apresentando assinatura 
neoproterozóica, outra mais antiga ( 2,0 Ga), o que gerou a proposição, respectivamente, do Cinturão Gurupi e do Cráton São Luís (Almeida et al., 1976). Baseados nessa subdivisão desenvolveram-se os modelos geotectônicos nas décadas seguintes. O limite entre as duas citadas províncias geocronológicas, na região do Gurupi, é definido pela Zona de Cisalhamento Tentugal, definida por Hasui et al. (1984), que coincide também com uma descontinuidade geofísica (Abreu \& Lesquer, 1985). Entretanto, a época de implantação dessa estrutura é uma das controvérsias ainda não resolvida, variando do Paleoproterozóico (Abreu, 1990) ao Neoproterozóico (Hasui et al., 1984). O mesmo problema diz respeito à evolução do cinturão Gurupi, existindo propostas de evolução monocíclica neoproterozóica (Costa \& Ricci, 1995), paleoproterozóica (Pastana, 1995), ou policíclica (Palheta, 2001).

Os dois domínios geocronológicos mostram também assinaturas litológicas, metamórficas e estruturais distintas. O domínio São Luís é constituído por granitóides cálcicoalcalinos (TTG) associados a subducção/arcos vulcânicos. Sequiências metavulcano-sedimentares metamorfizadas em facies xisto verde (localmente anfibolito) associam-se aos granitóides, sendo intrudidas pelos mesmos. Granitóides peraluminosos são subordinados e são um pouco mais novos que os granitóides cálcico-alcalinos. Estruturalmente é um domínio mais preservado de deformações tectônicas importantes.

O domínio Gurupi é constituído por uma seqüência metavulcano-sedimentar metamorfizada em facies xisto verde (localmente anfibolito), gnaisses (dominantemente ortoderivados) em facies anfibolito, localmente migmatizados, com intercalações de rochas metassedimentares em facies anfibolito. Esses conjuntos encontram-se altamente deformados por uma tectônica compressiva e direcional, o que provocou lenticularização e alongamento das unidades, e do domínio como um todo, segundo NW-SE. Granitóides peraluminosos, supostamente intrusivos nesses conjuntos, encontram-se também deformados, em maior ou menor proporção.

Os dados aqui sintetizados sugerem a existência de intensa atividade magmática, metamórfica e tectônica entre 2,2 e 2,0 Ga, com possível geração de crosta juvenil mais para o início desse ciclo e mais ligada ao domínio São Luís e maior retrabalhamento crustal (zircões herdados, idades modelo, $\boldsymbol{\varepsilon}_{\mathrm{Nd}}$ negativos) em direção ao final desse período, mais ligado ao domínio Gurupi. Os dois domínios possuem, portanto, uma história paleoproterozóica comum e é plausível inferir, de forma genérica, que a região tenha sido palco da colagem diacrônica (processos acrescionários e colisionais) de microcontinentes arqueanos (p. ex., porção ocidental do Cráton Oeste-Africano, porção sudeste do
Escudo das Guianas), arcos magmáticos, limitadas bacias oceânicas e/ou continentais e pequenos cinturões colisionais. Entretanto, a delimitação de cada um desses elementos (ambientes) envolvidos nessa colagem ainda carece de aprofundamento. O metamorfismo e, pelo menos, parte da estruturação regional devem ter acompanhado o final desse evento, conforme se deduz da idade $\mathrm{Rb}-\mathrm{Sr}$ em minerais mostrada pelo granitóide peraluminoso Maria $\mathrm{Su}$ prema. Esse quadro assemelha-se ao que é descrito para o mesmo período de tempo em outras porções da Plataforma Sul-Americana (p. ex., Brito Neves et al., 2000; Hartmann, 2002) e em áreas correlacionáveis à região do Gurupi, como a porção oriental da Guiana Francesa (Vanderhaeghe et al., 1998) e o Cráton Oeste-Africano (Hirdes \& Davis, 2002).

No Neoproterozóico, como reflexo da colagem orogênica brasiliana, muito bem marcada em regiões vizinhas, como Província Borborema, Faixa Araguaia e cinturões Pan-Africanos, atividade tectônica transcorrente teria afetado os conjuntos rochosos, provavelmente reativando a estruturação mais antiga, provocando a abertura dos sistemas Rb-Sr e K-Ar e levando à configuração atual do Cinturão Gurupi. Pouca litogênese está associada a esse período, sendo confirmado até o momento apenas o Granito Ney Peixoto. Apesar das características colisionais desse granitóide, a existência de uma segunda colisão é questionável e sua sugestão precisa ser acompanhada de outros elementos. A colocação desse tipo de granitóide em zonas transcorrentes é plausível (Koester et al., 2001). Não se descarta também a possibilidade de existência de sedimentação brasiliana, embora o seu rastreamento seja bastante difícil devido à ausência de fontes ígneas e metamórficas brasilianas suficientes para gerar detritos (i.e, mesmo que tenha havido sedimentação no Brasiliano, as fontes serão virtualmente todas Paleoproterozóicas).

A época do estabelecimento das bacias Vizeu, Igarapé de Areia e Piriá permanece incerta, podendo tratar-se de um ou mais períodos de sedimentação. Quanto ao nefelinasienito Boca Nova, é provável que a tentativa de ruptura da crosta amalgamada no Paleoproterozóico tenha possibilitado a sua intrusão.

Também é incerto o significado do Bloco Parnaíba $(\mathrm{Cu}-$ nha, 1986; Nunes, 1993), conjunto metamórfico não aflorante que constitui parte do embasamento da Bacia do Parnaíba. Seu arcabouço litológico é formado principalmente por gnaisses, xistos, quartzitos e milonitos, assinatura semelhante a do Cinturão Gurupi. Algumas dessas rochas foram datadas pelos métodos Rb-Sr e K-Ar (Kovach et al., 1976), com resultados similares aos do domínio Gurupi. Portanto, seu significado geotectônico, se faz parte do domínio Gurupi ou se constitui uma unidade autônoma, necessita ainda ser averiguado. 


\section{AGRADECIMENTOS}

Os dados $\mathrm{Rb}-\mathrm{Sr}$ do granitóide Jonasa foram obtidos durante o curso "Técnicas analíticas em geocronologia" feito pelo primeiro autor e ministrado pelos professores Candido Moura, Moacir Macambira e Thomas Scheller, do PARÁ-ISO. A eles e aos colegas que participaram do curso agradecemos a utilização desses dados inéditos. Os comentários feitos pelos revisores B. B. Brito Neves e J. M. Lafon foram muito apreciados. Contribuição ao projeto PRONEXCNPq-FAPESP66.2103/1998-80.

\section{REFERÊNCIAS BIBLIOGRÁFICAS}

ABREU, F. A. M. (1990) Evolução geotectônica do précambriano da região Meio Norte do Brasil e sua correlação com a África Ocidental. Belém, 440 p. Tese (Doutorado) - Universidade Federal do Pará.

ABREU, F. A. M.; LESQUER, A. (1985) Considerações sobre o pré-cambriano da região sul-sudoeste do Cráton São Luís. In: SIMPÓSIO DE GEOLOGIADAAMAZÔNIA, 2., Belém, 1985. Anais. Belém, SBG, v.1, p. 7-21.

ABREU, F. A. M.; VILLAS, R. N. N.; HASUI, Y. (1980) Esboço estratigráfico do pré-cambriano da região do Gurupi; Estados do Pará e Maranhão. In: CONGRESSO BRASILEIRO DE GEOLOGIA, 31., Camboriú, 1980. Resumos expandidos. Camboriú, SBG, v. 2, p. 647-658.

ALMARAZ, J. S. U.; CORDANI, U. G. (1969) Delimitação entre as províncias geocronológicas pré-cambrianas ao longo do Rio Gurupi. In: CONGRESSO BRASILEIRODE GEOLOGIA, 23., Salvador, 1969. Resumo das Conferências e Comunicações. p. 89 (Boletim Especial, 1).

ALMEIDA, H. G. G. (2000) Programa Grande Carajás-São Luís; folha SA.23 escala 1: 1.000.000: Estados do Pará e Maranhão. Brasília, CPRM. (Programa Levantamentos Geológicos Básicos do Brasil). CD-ROM.

ALMEIDA, F. F. M.; MELCHER, G. C.; CORDANI, U. G.; KAWASHITA, K.; VANDOROS, P. (1968) Radiometric age determinations from northern Brazil: Boletim da Sociedade Brasileira de Geologia, v. 17, p. 3-14.

ALMEIDA, F. F. M.; HASUI, Y.; BRITO NEVES, B. B. (1976) The Upper Precambrian of South America. Boletim. Instituto de Geociências US. São Paulo, v. 7, p. 45-80.

ALMEIDA, F. F. M.; BRITO NEVES, B. B.; CARNEIRO, C. D. R. (2000) The origin and evolution of the South American platform. Earth Science Review, v. 50, p. 77-111.

ANSDELL, K. M.; KYSER, T. K. (1994) Plutonism, deformation, and metamorphism in the Proterozoic Flin Flon greenstone belt, Canada: limits on timing provided by the single-zircon $\mathrm{Pb}$-evaporation technique. Geology, v. 19, p. 518-521.

BARBOSA, A. A.; LAFON, J. M. (1996) Geocronologia Pb$\mathrm{Pb}$ e $\mathrm{Rb}$-Sr de granitóides arqueanos da região de $\mathrm{Re}-$ denção - sul do Pará. Revista Brasileira de Geociências, v. 26, p. 255-264.

BETTENCOURT, J. S.; BORGES, W. R.; KORITIAKE, M. (1991) The Cachoeira gold deposit, Gurupi belt, Pará, Brazil: geological setting, structure and mineralization. In: LADEIRA, E.A. (ed.) Brazil Gold'91. Rotterdam, A. A. Balkema, p. 203-208.

BRITO NEVES, B. B.; CORDANI, U.G. (1991) Tectonic evolution of South America during the Late Proterozoic. Precambrian Research, v. 53, p. 23-40.

BRITO NEVES, B. B.; SANTOS, E. J.; VAN SCHMUS, W. R. (2000) Tectonic history of the Borborema Province. In: CORDANI, U.G.; MILANI, E. J.; THOMAZ FILHO, A.; CAMPOS, D. A. (eds.) Tectonic evolution of South America. Rio de Janeiro. p. 151-182.

CORDANI, U. G.; MELCHER, G. C.;ALMEIDA, F. F.M.(1968) Outline of the precambrian geochronology of South America. Canadian Journal of Earth Sciences, v. 5, p. 629-632.

COSTA, J. B. S.; HASUI, Y. (1997) Evolução geológica da Amazônia. In: COSTA, M. L.; ANGÉLICA, R. S. (coords.) Contribuições à geologia da Amazônia. Belém, SBG-NO. v.1, p. 15-90.

COSTA, J. L. (2000) Programa Grande Carajás: Castanhal, Folha SA.23-V-C-Estado do Pará. Belém, CPRM. (Programa Levantamentos Geológicos Básicos do Brasil). CD-ROM

COSTA, J. L.; ARAUJO, A. A. F.; VILLAS BOAS, J. M.; FARIA, C.A. S.; SILVANETO, C. S.; WANDERLEY, V. J. R. (1977) Projeto Gurupi. DNPM/CPRM, 258 p. (Relatório inédito)

COSTA, J. L.; RICCI, P. S. F. (1995) A Faixa de cisalhamento Gurupi e o cenário colisional do Cráton São Luís. In: SIMPÓSIO NACIONAL DE ESTUDOS TECTÔNICOS, 5., Gramado, 1995. Boletim de Resumos Expandidos. Gramado, SBG-RS, p. 18-20.

CUNHA, F. M. B. (1986) Evolução paleozóica da Bacia do Parnaíba e seu arcabouço tectônico. Rio de Janeiro, 107 p. Dissertação (Mestrado) - Instituto de Geociências, Universidade Federal do Rio de Janeiro.

FRANCISCO, B. H. R.; LOWENSTEIN, P.; SILVA, O. F.; SILVA, G. G. (1971) Contribuição à geologia da Folha São Luís (SA.23) no Estado do Pará. Boletim.Museu Paraense Emílio Goeldi. Série Geologia, v. 17, p. 1-40. 
HARTMANN, L. A. (2002) The Mesoproterozoic Supercontinent Atlantica in the Brazilian Shield - review of geological and $\mathrm{U}-\mathrm{Pb}$ zircon and $\mathrm{Sm}-\mathrm{Nd}$ isotopic evidence. Gondwana Research, v. 5, p. 157-163.

GORAYEB, P. S. S.; GAUDETTE, H. E.; MOURA, C. A. V.; ABREU, F. A. M. (1999) Geologia e geocronologia da Suíte Rosário, nordeste do Brasil, e sua contextualização geotectônica. Revista Brasileira de Geociências, v. 29, p. 571-578.

HASUI, Y.; ABREU, F. A. M.; VILLAS, R. N. N. (1984) Província Parnaíba. In: ALMEIDA, F. F. M.; HASUI, Y. (coords.) O Pré-Cambriano no Brasil. São Paulo, Edgard Blücher, p. 36-45.

HIRDES, W., DAVIS, D. W. (2002) U/Pb Geochronology of paleoproterozoic rocks in the Southern Part of the Kedougou-Kéniéba Inlier, Senegal, West Africa: evidence for diachronous accretionary development of the Eburnean Province. Precambrian Research, v. 118, p. 83-99.

HURLEY, P. M.; ALMEIDA, F. F. M.; MELCHER, G. C.; CORDANI, U. G.; RAND, J. R.; KAWASHITA, K.; VANDOROS, P.; PINSON, W. H.; FAIRBAIRN, H. W. (1967) Test of continental drift by comparison of radiometric ages. Science, v. 157, p. 495-500.

HURLEY, P. M.; MELCHER, G. C.; PINSON, W. H.; FAIRBAIRN, H. W. (1968) Some orogenic episodes in South America by K-Ar and whole-rock Rb-Sr dating. Canadian Journal of Earth Sciences, v. 5, p. 633-638.

JORGE-JOÃO, X. S. (1980) O litchfieldito Boca Nova no nordeste do Estado do Pará: aspectos petroquímicos e implicação econômica. Belém, CPRM. (Relatório inédito).

KLEIN, E. L.; KOPPE, J. C.; MOURAC. A. V. (2002) Geology and geochemistry of the Caxias gold deposit, and geochronology of the gold-hosting Caxias microtonalite, São Luís Craton, northern Brazil. Journal of South American Earth Science, v. 14, p. 837-849.

KLEIN, E. L.; MOURA, C. A. V. (2001a) Age constraints on granitoids and metavolcanic rocks of the São Luís Craton and Gurupi Belt, northern Brazil: implications for lithoestratigraphy and geological evolution. International Geology Review, v. 43, p. 237-253.

KLEIN, E. L.; MOURA, C.A. V. (2001b) Síntese geológica e geocronológica do Cráton São Luís e Cinturão Gurupi: implicações para a litoestratigrafia e modelos geotectônicos. In: SIMPÓSIO DE GEOLOGIADAAMAZÔNIA, 7., Belém, 2001. Resumos Expandidos. Belém, SBG. (CD-ROM).

KOBER, B. (1986) Whole-grain evaporation for ${ }^{207} \mathrm{~Pb} /{ }^{206} \mathrm{~Pb}$ age-investigations on single zircons using a double-fila- ment source. Contributions to Mineralogy and Petrology, v. 93, p. 482-490.

KOESTER, E.; ROISENBERG, A.; FERNANDES, L. A. D.; SOLIANI JR., E.; NARDI, L. V. S.; KRAEMER, G. (2001) Petrologia dos granitóides sintectônicos à zona de cisalhamento transcorrente Dorsal de Canguçu, Encruzilhada do Sul, RS. Revista Brasileira de Geociências, v. 31, p. 131-140.

KOVACH, A.; FAIRBAIRN, H. W.; HURLEY, P. M.; BASEI, M.A. S.; CORDANI, U. G. (1976) Reconnaissance geochronology of basement rocks from the Amazonas and Maranhão basins in Brazil. Precambrian Research, v. 3, p. 471-480.

LOWELL, G. R. (1985) Petrology of the Bragança batholith, São Luís craton, Brazil. In: BOARD, W.L.; WU, LI-JEN. The crust: the significance of granites-gneisses in the lithosphere. Athens, Theophrastus. p. 13-34.

NUNES, K. C. (1993) Interpretação integrada da Bacia do Parnaíba com ênfase nos dados aeromagnéticos. In: CONGRESSO INTERNACIONAL DA SOCIEDADE BRASILEIRA DE GEOFÍSICA, 3., Rio de Janeiro, 1993. Resumos Expandidos. Rio de Janeiro, SBgf. v. 1, p. 152-157.

PALHETA, E. S. M. (2001) Evolução geológica da região nordeste do Estado do Pará com base em estudos estruturais e isotópicos de granitóides. Belém, 144 p. Dissertação (Mestrado) - Centro de Geociências, Universidade Federal do Pará.

PASTANA, J. M. N. (1995) Programa Grande Carajás. Turiaçu/Pinheiro, folhas SA.23-V-D/SA.23-Y-B : Estados do Pará e Maranhão. Brasília, CPRM, 205p. (Programa Levantamentos Geológicos Básicos do Brasil).

SÖDERLUND, U. (1996) Conventional U-Pb dating versus single-zircon $\mathrm{Pb}$ evaporation dating for complex zircons from a pegmatite in the high-grade gneisses of southwestern Sweden. Lithos, v. 38, p. 93-105.

STACEY, J. S.; KRAMERS, J. D. (1975). Approximation of terrestrial lead isotope evolution by a two-stage model. Earth Planetary Science Letters, v. 26, p. 207-221.

TORRESINI, C. A. (2000) The Gurupi gold deposits (Cipoeiro and Chega Tudo), Gurupi belt, Pará, Brazil: geology and mineralization. In: INTERNATIONAL GOLD SYMPOSIUM, 14., Lima, Peru. (CD-ROM).

VANDERHAEGHE, O.; LEDRU, P.; THIÉBLEMONT, D.; EGAL, E.; COCHERIE, A.; TEGYEY, M.; MILÉSI, J. P. (1998) Contrasting mechanism of crustal growth. Geodynamic evolution of the Paleoproterozoic granitegreenstone belts of French Guiana. Precambrian Research, v. 92, p. 165-193. 
VILLAS, R. N. N. (1982) Geocronologia das intrusões ígneas na bacia do rio Guamá, nordeste do Estado do Pará. In: SIMPÓSIODE GEOLOGIADAAMAZÔNIA, 2., Belém, 1982. Anais. Belém, SBG, v. 1, p. 233-247.

VILLAS, R. N. N. (2001) O granito de duas micas Ney Peixoto, nordeste do Estado do Pará: caracterização petrográfico-petroquímica e contexto tectônico. In: SIMPÓSIO DE GEOLOGIADAAMAZÔNIA, 7., Belém, 2001. Resumos Expandidos. Belém, SBG-NO. (CD-ROM).

WANDERLEY FILHO, J. R. (1980) Geocronologia do Granito Mirasselvas, nordeste do Pará. In: CONGRESSO BRASILEIRODEGEOLOGIA, 31., Camboriú, 1980. Abstracts. Camboriú, SBG, v. 2, p. 426.

YAMAGUTI, H.S.; VILLAS, R.N.N. (1999) A mineralização aurífera de Montes Áureos (NW do Maranhão): aspectos geológicos e fluidos mineralizantes. In: SIMPÓSIO DE GEOLOGIA DA AMAZÔNIA, 6., Manaus, 1999. Boletim de Resumos Expandidos. Manaus, SBG, p. 102-105. 